\title{
APRESENTAÇÃO
}

\section{Pesquisa em educação: novos horizontes e possibilidades teórico-metodológicas}

O número 40 da Revista da FAEEBA - Educação e Contemporaneidade dedica-se à temática da Pesquisa em Educação ao apresentar reflexões epistemológicas e teórico-metodológicas relacionadas aos processos de pesquisa no/para o campo educacional. Este número se estrutura a partir de um conjunto de textos organizados em dois grandes eixos: o primeiro reúne artigos que problematizam a necessidade do rigor epistemológico e o segundo apresenta a produção dos autores que se dedicaram às dimensões metodológicas do ato de pesquisar em Educação. Nesse sentido, oferecemos ao público um consistente debate sobre as diversas abordagens dos fenômenos educativos e educacionais na contemporaneidade. As reflexões acerca da dimensão ontológica da Educação e da pesquisa qualitativa como práxis humana fazem a abertura do número. Os demais artigos verticalizam reflexões teórico-metodológicas sobre diversas dimensões da práxis educativa. Tais opções epistemológicas e análises teórico-metodológicas evidenciam singularidades e diversidades de abordagens de pesquisas sobre processos e fenômenos educativos e educacionais.

As discussões epistemológicas são aglutinadas em dois textos iniciais que teorizam sobre pesquisa qualitativa e as bases filosóficas e ontológicas do campo educacional numa perspectiva fenomenológica e dialética. $\mathrm{O}$ artigo de Lucila Pesce e Claudia Barcelos de Moura Abreu, intitulado Pesquisa qualitativa: considerações sobre as bases filosóficas e os princípios norteadores, configura-se um estudo bibliográfico, ao apresentar princípios norteadores sobre a pesquisa qualitativa e suas implicações com a Fenomenologia e a Dialética. O texto de Liége Maria Sitja Fornari e Elizeu Clementino de Souza $A$ verdade ontológica de Luigi Pareyson: implicações para a pesquisa em educação utiliza-se de ideias do filósofo Luigi Pareyson para sistematizar questões sobre verdade, pensamento e interpretação, ao analisar características do pensamento expressivo e do pensamento revelativo, destacando potencialidades para o campo da produção do conhecimento em Educação.

Um segundo bloco de textos organiza-se na perspectiva de discussão sobre pesquisa e questões curriculares, sistematizando eixos metodológicos para estudos no campo do currículo e para a análise de textos curriculares. O artigo Pesquisas pós-críticas em educação: notas metodológicas para investigações com currículos de gosto duvidoso, de Marlécio Maknamara e Marlucy Alves Paraíso, objetiva destacar algumas questões teórico-metodológicas em torno de pesquisas em Educação que se pretendem pós-críticas. Ao tomar o ensino de música como referência, os autores realizam análises discursivas inspiradas em Michel Foucault. Em seguida, o artigo Discurso, demandas e fronteira: articulações teórico-metodológicas na análise de textos curriculares, de Carmen Teresa Gabriel, foca na análise de processos de produção e circulação do conhecimento validado e legitimado em diferentes contextos de formação, ante os discursos e fazeres curriculares. $\mathrm{O}$ trabalho ancora-se em abordagens discursivas na 
perspectiva pós-fundacional, ao destacar algumas implicações desta dimensão teórico-metodológica nos processos de investigação desenvolvidos pelo grupo de pesquisa, ao sublinhar potencialidade analítica das categorias "demanda" e "fronteira" sobre a fixação de sentidos de "conhecimento escolar/acadêmico".

Outros três textos tematizam dimensões da etnografia, da pesquisa colaborativa e do estudo de caso em Educação, contribuindo significativamente para a ampliação de questões teóricas sobre esses métodos de pesquisa. O artigo de Amurabi Oliveira Por que etnografia no sentido estrito e não estudos do tipo etnográfico em educação? sinaliza ampliação da utilização de metodologias qualitativas no campo educacional e modos instrumentais - como processo de coleta de dados - e como a etnografia tem sido apropriada em diversas pesquisas educacionais, ao esclarecer alguns de seus pressupostos epistemológicos, e refutando argumentos utilizados para a sua negação. $\mathrm{O}$ artigo (Re)visitando categorias teórico-metodológicas a partir da pesquisa crítica de colaboração, de Ilka Schapper e Núbia Santos, sistematiza fertilidades e potencialidades da Pesquisa Crítica de Colaboração (PCCol), a partir da ressignificação de duas categorias teórico-metodológicas - sentido e significado e zona de desenvolvimento proximal - inscritas nos trabalhos realizados pelo Grupo de Pesquisa Linguagem, Educação, Formação de Professores e Infância (LEFoPI/CNPq/UFJF). O artigo de Marli André, intitulado O que é um estudo de caso qualitativo em Educacão?, discute questões relacionadas ao rigor na pesquisa e o conceito e os fundamentos do estudo de caso qualitativo em Educação, destacando suas fases e exemplificando com experiências realizadas com estudos de caso desenvolvidos no contexto de uma pesquisa que avalia o Programa de Formação de Professores em Exercício (PROFORMAÇÃO).

Questões sobre pesquisa biográfica, escritas de si e entrevistas narrativas também mobilizam pesquisadores quando refletem sobre princípios e modos como se vem utilizando os métodos biográficos no campo educacional como abordagem ou como técnica de pesquisa. Inicia esse bloco de texto o artigo Identidade, relação e contexto: uma releitura epistemológica dos métodos biográficos, de Laura Formenti, ao desenvolver reflexões teóricas, epistemológicas e metodológicas sobre os métodos biograficamente orientados na pesquisa sobre educação de adultos, numa perspectiva sistêmica e construtivista. Conceitos de identidade e relações contextuais são explorados no texto, tendo em vista indicar possibilidades de análises de narrativas, mediante apreensão de trajetórias identitárias e de formação, bem como modos de análise implicados com o "pacto" e o "olhar" dos sujeitos que narram, da reflexividade pessoal e dispositivos colaborativos entre sujeitos em formação e pesquisadores. $\mathrm{O}$ texto de Christophe Niewiadomski Pesquisa biográfica, clínica narrativa e análise da relação com a escrita descreve um dispositivo de produção biográfica e de análise relativa à escrita, tendo em vista explorar, em uma situação de grupo, a parte de invalidação ou de autorização ligada às representações da escrita para os participantes, no contexto de um exemplo clínico, questionando articulações entre o registro intrapsíquico e sociocultural na construção da relação com a escrita biográfica, na vertente da sociologia clínica. Encerra esse bloco de textos o artigo de Wivian Weller e Sinara Pollom Zardo, intitulado Entrevista narrativa com especialistas: aportes metodológicos e exemplificação, ao analisar questões metodológicas vinculadas à utilização de entrevista narrativa e da entrevista com especialistas, bem como suas contribuições para a pesquisa qualitativa em Educação, com base em reflexões sobre a Fenomenologia Social de Alfred Schütz. Questões teóricas sobre entrevistas narrativas são sistematizadas, a partir do modo como desenvolve Fritz Schütze, bem como 
aspectos metodológicos da entrevista com especialistas apontados por Michael Meuser e Ulrike Nagel. Busca-se no final do texto explicitar resultados de uma pesquisa realizada com base em entrevistas narrativas com gestores educacionais responsáveis pela implementação de políticas de inclusão nos sistemas de ensino no Distrito Federal.

A problematização dos processos formativos e considerações sobre processos identitários se fazem presente nos artigos de Júlio Emílio Diniz-Pereira e Alexandra Lima da Silva. O mesmo tema é desenvolvido no texto em coautoria de Rosana Aparecida Fernandes e Jarbas Santos Vieira. Enquanto os dois primeiros autores tematizam aspectos formativos da docência, a preocupação central do terceiro texto é a formatividade da aprendizagem.

Júlio Emílio Diniz-Pereira, no artigo intitulado A construção do campo da pesquisa sobre formação de professores, propõe uma abordagem contextualizada da estruturação do campo de pesquisa sobre formação de professores no cenário global e nacional. A atenção do autor dirige-se especialmente às principais modificações ocorridas nesse campo em termos de temáticas e metodologias de pesquisa. Em Um educador itinerante: o caso Rocha Pombo, de Alexandra Lima da Silva, a autora parte de uma perspectiva dialética entre a dimensão histórica e biográfica para analisar a influência do intelectual Rocha Pombo na formação intelectual do estado do Paraná. A chave analítica está posta nos significados do viajar na trajetória desse intelectual. Destacando um expressivo filósofo que tem contribuído para qualificar o debate sobre pesquisas em Educação, o artigo intitulado Estudar e aprender em duas cartografias, de Rosana Aparecida Fernandes e Jarbas Santos Vieira, provoca indagações fundamentais apoiados em Gilles Deleuze. O tema central do texto é a interrogação sobre o que efetivamente impulsiona o aprender e leva os corpos a ultrapassarem seus limites e a comporem novos aprendizados.

Os próximos cinco artigos se debruçam, especificamente, sobre as questões relativas ao método e sua aplicação. No texto intitulado Games e educação: desvendando o labirinto da pesquisa, a autora Lynn Alves objetiva mapear as pesquisas existentes no Banco de Teses e Dissertações da Capes, na área de Educação, com o propósito de identificar as principais tendências teórico-metodológicas das investigações que se dedicam ao tema dos jogos eletrônicos. Sustentadas intelectualmente em princípios teóricos propostos por Bahabha, Bakthin e Spivak, as autoras Flávia Miller Naethe Motta e Rita de Cássia Prazeres Frangella, no texto intitulado Descolonizando a pesquisa com criança: uma leitura pós-colonial de pesquisa, realizam um importante diálogo sobre as implicações de dar voz ao outro na/e pela pesquisa. Por sua vez, Graciela Morgade, no artigo Notas epistemológicas desde una investigación feminista sobre educación sexual, contribui para o debate metodológico sobre a temática, a partir da problematização fundamental na contemporaneidade sobre a reflexividade feminista na produção do conhecimento. Dando visibilidade ao importante debate referente à educação sexual e às políticas educativas implementadas na Argentina, a autora questiona as formas tradicionais e patriarcais de construção e divisão do saber. No artigo intitulado A crise ambiental em evidência: análise do discurso foucaultiano - modos de fazer pesquisa em educação, as autoras Virgínia Tavares Vieira e Paula Corrêa Henning, apoiadas em pensadores como Michel Foucault, Félix Guattari, Isabel Carvalho e Leandro Belinaso Guimarães, problematizam a análise do discurso como ferramenta metodológica. O objetivo central do texto é identificar e refletir sobre a trama discursiva que vem compondo o campo da Educação ambiental. Marcus Vinícius Medeiros Pereira fecha este bloco de textos propondo importante questionamento metodológico acerca da 
distinção entre pesquisas denominadas "estado do conhecimento" e "estado da arte". No artigo intitulado Fundamentos teórico-metodológicos da pesquisa em educação: o ensino superior em música como objeto, o autor analisa o estado do conhecimento das pesquisas em cursos de Licenciatura em Música do Brasil.

Na seção "Estudos" são contemplados três artigos. Exercício de intimidade: uma aproximação com a aprendizagem da escrita de si é o primeiro deles. A autora Ana Chrystina Venancio Mignot toma como fonte de pesquisa as cartas escritas por crianças, a fim de analisar a centralidade que a escrita de cartas teve na aprendizagem dos códigos de civilidade, no autoconhecimento, na formação moral e na internalização de normas gramaticais. Metodologicamente a autora pontua fundamental distinção entre escrever sobre infância e na infância. O segundo artigo dessa seção, de autoria de Taisa de Souza Ferreira e Marco Antonio Leandro Barzano, intitulado Modos de ver, sentir e questionar: a presença do gênero e da sexualidade no curso de pedagogia, aborda questões relacionadas aos sentidos e significados sobre gênero e sexualidade no âmbito da formação inicial de professores (as) no curso de Pedagogia. Finaliza essa seção o artigo Memórias digitais: escritas de si nas comunidades escolares do ORKUT, de Robson Fonseca Simões. O autor toma narrativas biográficas como autorrelatos nas redes sociais do Orkut. Em tempos de tecnologias digitais, as redes sociais constituem-se em lócus privilegiado de relações humanas e um campo fértil para investigação.

Desejamos que este número contribua para qualificar o diálogo sobre as pesquisas no campo educacional, na medida em que possa ampliar debates sobre metodologias e abordagens diversas que circunscrevem estudos sobre diferentes processos e fenômenos da Educação em suas múltiplas relações.

Salvador, primavera de 2013

Elizeu Clementino de Souza Liége Maria Sitja Fornari 